Original Article

\title{
A CORRELATIVE STUDY TO ASSESS THE PSYCHOLOGICAL WELLBEING AND SELF-ESTEEM AMONG ADULT CHILDREN OF M ENTALLY ILL PARENT/ S IN SELECTED HOSPITAL OF UDUPI DISTRICT
}

\author{
K. Jayakrishnan ${ }^{1}$, Shalini ${ }^{2} \&$ Savitha $^{3}$ \\ ${ }^{1}$ Student M Sc. (N) ${ }^{2,3}$ Assistant Professors, Department of Psychiatric/ Mental Health Nursing, \\ M anipal College of Nursing Manipal, Manipal University, M anipal - 576 104, Karnataka, India. \\ Correspondence : \\ Savitha \\ Assistant Professor, Department of Psychiatric / M ental Health Nursing, Manipal College of Nursing Manipal, \\ M anipal University, Manipal - 576 104, Karnataka, India. \\ Mobile : +9194817 60372 E-mail : chaitrachandan@yahoo.co.in
}

\begin{abstract}
:
Introduction : Caregivers across the world, who are often unrecognised and under supported, are deeply and personally impacted by the care they provide. The recognition of high levels of caregiver morbidity demands a holistic approach and nurses need to be more responsive to the needs of carers and care-recipients rather than focussing on the patient alone. Aims and Objectives: to determine the psychological wellbeing of adult children with mentally ill parent/s, to assess the level of self-esteem of adult children of their mentally ill parent/s, and to find the relationship between psychological wellbeingand self-esteem.
\end{abstract}

Study design : descriptive correlational study design.

Methods and materials: study was conducted among 63 adult children of mentally ill parents by using convenient sampling technique. A survey approach was used for the study. Tools used for the study were Demographic Proforma, Psychological wellbeing scale, and Rosenberg's self-esteem scale.

Results : M ajority, 35 (55.6\%) of the samples were found to be having high psychological wellbeing. 27 (42.9\%) of the samples were intermediate psychological wellbeing and only 1 (1.6\%) participant was having low psychological wellbeing. Majority (68.3\%) of the samples were found to be having normal self-esteem. (30.2\%) of the samples were with low self-esteem and only (1.6\%) participant was having high self-esteem. There is no significant correlation was found between psychological wellbeing and self-esteem $(r=0.044, p=$ 0.730).

Key words: adult children, psychological wellbeing, self-esteem, mentally ill parent/s

\section{Introduction:}

Caring for older frail and chronically ill family members is not without costs; although the caregiving role can be rewarding, it can also be highly stressful. It is now well established that family members who provide care to frail and disabled older adults are at greater risk for

\begin{tabular}{|c|}
\hline Access this article online \\
\hline Quick Response Code \\
\hline
\end{tabular}
experiencing health problems, as well as psychiatric morbidities, such as anxiety and d e pres s i ve symptomology, than noncaregivers. Through studies it is understood that a caregiver will go under a lot of psychological demand that influences the psychological wellbeing, self-esteem and perceived stigma of the caregivers ${ }^{1}$.

A study conducted by K. S. Shaji, Roy K. George, Martin J. Prince and K. S. Jacob in Kerala on 2007 to observe the behavioural symptoms and caregiver burden in dementia, whose sample consisted of $79.3 \%$ women who were living with their families, revealed that symptoms like activity disturbances; aggressiveness and delusions in particular are indeed troublesome to the caregiver and that many factors might positively and negatively influence the experience of caregiver burden and modulate the psychological impact of providing care to the demented relative. $^{2}$ 
In a study conducted by Papastavrou E., et al. at Cyprus on family caregiver burden among volunteer sample of 172 caregiver/care recipient dyads who were all patients suffering from probable Alzheimer's type dementia and were recruited from neurology clinics, suggested that irrespective of the community, caregivers have high level of burden. The findings reveal that $68.02 \%$ of caregivers were highly burdened and even, 65\% exhibited depressive symptoms and the burden was related to patient psychopathology and caregiver sex, income and level of education. It has been observed that women are more likely to experience social restrictions because of their caring role (Montgomery 1996), and they experience higher levels of burden when compared with men caregivers (Thomson et al. 2004). It was also found that caregivers with higher education and better remuneration had lower levels of burden; it seems that these factors may function as buffers to the stressors of care giving. ${ }^{3}$

A study conducted by Linju Ann Alias on 2011 to assess the co-dependency and depressive symptoms among caregivers of alcoholics using 140 caregivers from 3 hospitals in Udupi district revealed that $10 \%$ caregivers has severe co-dependency and 15\% caregivers has severe depressive symptoms and that there is no association between co-dependency and depressive symptoms. ${ }^{4}$

Caregivers across the world, who are often unrecognized and under supported, are deeply and personally impacted by the care they provide. Despite the burdens they shoulder, many caregivers report enormous positive feelings about the care they provide. Health professionals, mental health nurses have an important role to acknowledge the burden of the caregivers. Caregivers need resources and support to sustain this loving and valuable care of those with psychiatric disorders ${ }^{1}$.

\section{Materialsand methods:}

A descriptive correlational study design was adopted and study was conducted among 63 adult children of mentally ill parents. After obtaining the administrative permission, the researcher approached the study subjects, explained the purpose of the study and obtained their consent after assuring them the confidentiality of the data. Participants were adult children who were above the age of 18 years and had at least one parent, who had been diagnosed with Schizophrenia, Affective disorder or Organic mental disorder, as per the ICD-10 criteria, for more than 6 months. Adult children having any physical illness, past/current psychiatric illness, unwilling to participate in the study and those who were illiterate were excluded from the study. Adult children were selected through purposive sampling technique from the psychiatry OPDs and wards of Kasturba hospital, M anipal.

Data was collected using Demographic Proforma, Psychological wellbeing scale (PWB), by Bhogle and Jaiprakash, 1995 and Rosenberg's self-esteem scale. Psychological wellbeing tool is a 28 item questionnaire in a forced choice (Yes/ No) format. In the tool, 10 statements $(4,5,6,10,12,14,15,16,21$ and 24$)$ are negative and rest 18 statements are positive. Scores are classified as (0-9) as low psychological wellbeing, (10-20) as intermediate psychological wellbeing and (21-28) as high psychological wellbeing. Higher the score, higher the psychological wellbeing ${ }^{5}$. Rosenberg self-esteem scale is a structured rating scale to assess self-esteem of general population, developed by Rosenberg (1965). Rosenberg reported that internal consistency reliability of the instrument range from ( $r=0.85$ to 0.88 ). The scale consists of 10 items; each item is scored on a four point scale under the options: strongly agree, agree, disagree, and strongly disagree, five statements were positive and five negative with a total score of 30. Scores are classified as below 15 as low selfesteem, 15-25 scores as normal self-esteem and above 25 are considered as high self-esteem. Higher the scores, higher the self-esteem ${ }^{6}$.

\section{Statistical Methods:}

Descriptive (frequency and percentage) and inferential (Spearman' correlational coefficient) statistics were used for the analysis of the study. Non parametric (Spearman correlation coefficient) test was used to find the correlation between psychological wellbeing and Self-esteem. 
Results:

Table 1: Frequency and percentage distribution of sample characteristics

\begin{tabular}{|c|c|c|}
\hline Sample characteristics & Frequency (f) & Percentage \\
\hline \multicolumn{3}{|l|}{ Age (in years) } \\
\hline $18-27$ & 31 & 49.2 \\
\hline $28-37$ & 13 & 29.6 \\
\hline $38-47$ & 11 & 17.5 \\
\hline 48- 57 & 3 & 4.8 \\
\hline 58 and above & 5 & 7.9 \\
\hline \multicolumn{3}{|l|}{ Gender } \\
\hline Male & 28 & 44.4 \\
\hline Female & 35 & 55.6 \\
\hline \multicolumn{3}{|l|}{ Religion } \\
\hline Hindu & 54 & 85.7 \\
\hline Christian & 3 & 4.8 \\
\hline Muslim & 6 & 9.5 \\
\hline \multicolumn{3}{|l|}{ M arital status } \\
\hline Unmarried & 31 & 50 \\
\hline Married & 28 & 40 \\
\hline Widow/widower & 4 & 10 \\
\hline \multicolumn{3}{|l|}{ Educational status } \\
\hline No formal education & 5 & 7.9 \\
\hline Up to $8^{\text {th }}$ standard & 11 & 17.4 \\
\hline Up to $10^{\text {th }}$ standard & 10 & 15.8 \\
\hline Pre university & 9 & 14.2 \\
\hline Graduation & 22 & 34.9 \\
\hline Post-graduation and above & 6 & 9.5 \\
\hline \multicolumn{3}{|l|}{ Occupation } \\
\hline Professional & 18 & 28.6 \\
\hline Non professional & 25 & 39.7 \\
\hline Not working & 20 & 31.7 \\
\hline \multicolumn{3}{|l|}{ Monthly income (in Rupees) } \\
\hline $1,000-5000$ & 23 & 36.5 \\
\hline $5001-10,000$ & 11 & 17.5 \\
\hline $10,001-15,000$ & 11 & 17.5 \\
\hline $15,001-20,000$ & 8 & 12.7 \\
\hline$>20,000$ & 10 & 15.9 \\
\hline \multicolumn{3}{|l|}{ Parent/s's current diagnosis } \\
\hline Schizophrenia & 18 & 28.6 \\
\hline Mood disorders & 28 & 44.4 \\
\hline Organic psychiatric disorder & 17 & 27.0 \\
\hline \multicolumn{3}{|l|}{ Duration of parent/s illness } \\
\hline 6 months - 1 year & 18 & 28.6 \\
\hline$>1$ year- 2 years & 17 & 27 \\
\hline$>2$ years- 5years & 17 & 27 \\
\hline$>5$ years- 10 years & 4 & 6.3 \\
\hline$>10$ years & 7 & 11.1 \\
\hline
\end{tabular}

$n=63$

Number of times your parent/ $s$ is admitted to any hospital for mental illness

$\begin{array}{lcc}\text { Never } & 34 & 54.0 \\ \text { once } & 16 & 25.4 \\ \text { Twice } & 7 & 11.1 \\ 3 \text { times or more } & 6 & 9.5\end{array}$

\begin{tabular}{lcc}
\hline Sample characteristics & Frequency (f) & Percentage (\%) \\
\hline Duration of the current hospitalisation of your parent/ $\mathbf{s}$ \\
No hospitalization & 39 & 61.9 \\
1 day- 6 days & 11 & 17.5 \\
$7-13$ days & 9 & 14.3 \\
$14-20$ days & 4 & 6.3 \\
\hline
\end{tabular}

Figure 1: Pie diagram showing the percentage distribution of psychological wellbeing in adult children of mentally ill parent/s.

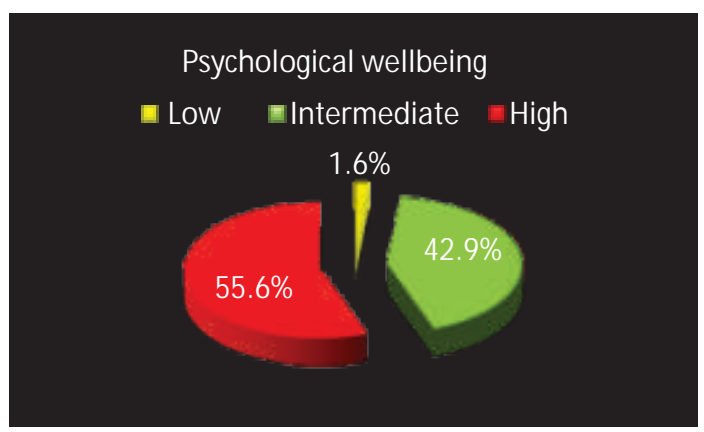

The data presented in figure 1 shows that out of 63 participants, Majority 35 (55.6\%) of the samples were found to be having high psychological wellbeing. $27(42.9 \%)$ of the samples were with intermediate psychological wellbeing and only 1 (1.6\%) participant was having low psychological wellbeing.

Figure 2 : Doughnut diagram showing the percentage distribution of self-esteem in adult children of mentally ill parent/s

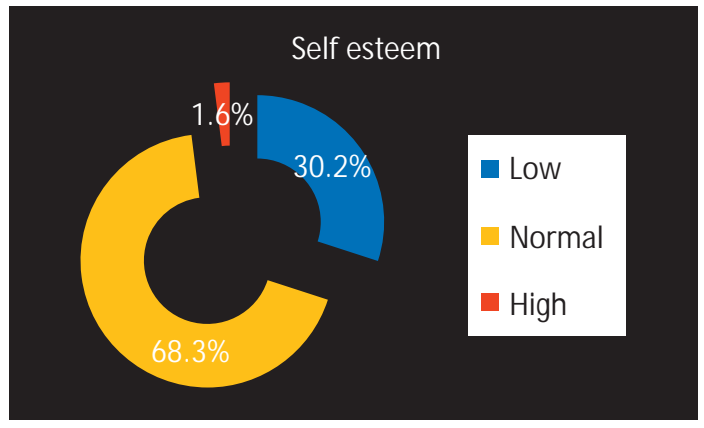

The data presented in Figure 2 shows that out of 63 participants majority (68.3\%) of the samples were found to be having normal self-esteem. 19 (30.2) samples were with low self-esteem and only 1 (1.6\%) participant was having high self-esteem.

Table 2: Correlation between the psychological wellbeing and self-esteem $n=63$

\begin{tabular}{lcc}
\hline Variables & $(\boldsymbol{r})$ value & $\mathbf{p}$ value \\
\hline Psychological wellbeing and self-esteem & 0.044 & 0.730 \\
\hline
\end{tabular}

The data in presented in the table 2 shows that there is no significant correction between psychological wellbeing and selfesteem $(r=0.044, p=0.730)$. 


\section{Discussion :}

In the present study, out of 63 participants, majority, 35 $(55.6 \%)$ of the samples were found to be having high psychological wellbeing. 27 (42.9\%) of the samples were with moderate psychological wellbeing. This finding supports the reports of a study conducted by Roy $\mathrm{K}$. George et al. to observe the behavioral symptoms and caregiver burden of dementia patients revealed that many factors might positively and negatively influence the experience of caregiver burden and modulate the psychological impact of providing care to the demented relative. $^{2}$

The study also found that out of 63 participants, majority, $43(68.3 \%)$ of the samples were found to be having normal self-esteem. 19 (30.2\%) of the samples were with low selfesteem and only 1 (1.6\%) participant was having high selfesteem. A study by Kathleen, LeClearand O'Connell about the experiences, needs of, and interventions for children of seriously mentally ill mothers was found that there was a severe disruption of self-esteem for adult children of their mentally parents. ${ }^{7}$

In the present study, no correlation was found between psychological wellbeing and self-esteem $(r=0.044, p=$ 0.730 ) among adult children of mentally ill parents. The findings are contradicting to the finding by a study conducted by Noonan AE and Tennstedt SL, in new England

\section{References:}

1. Othman Z, Salleh M. Burden of Care and Social Behaviour Problem of Patients with Schizophrenia. International Medical Journal Vol. 15, [citied 2008] ; $4: 269-274$.

2. Shaji KS, George K, Prince J, and Jacob KS. Behavioural symptoms and caregiver burden in dementia. Indian journal of psychiatry. [citied 2009];51(1): 45-49.

3. Papastavrou E, Kalokerinou A, Papacostas SS, Tsangari H \& Sourtzi P. Caring for a relative with dementia: family caregiver burden. Journal of Advanced Nursing. [citied 2007]; 58(5):446-457.

4. Alias L A. A study to assess the co-dependency and depressive symptoms among the care givers of alcoholics of Udupi district, Karnataka. Dissertation submitted to M anipal University. July 2011.

5. Bhogle S, Prakash IJ (1995). Development of the psychological wellbeing(PWB) questionnaire. Journal of personality and clinical studies. Vol 11; p 5-9. shows that the relationship between meaning in caregiving that is, positive beliefs about the caregiving situation and the self as caregiver and the psychological well-being of 131 caregivers to community residing frail elders. Measures of well-being included depression, self-esteem, mastery, role captivity, and loss of self. Meaning in caregiving explained a significant portion of correlation in wellbeing and self-esteem scores even after demographic and stressor variables had been controlled. ${ }^{8}$

\section{Conclusion :}

The present study found that majority, (55.6\%) of the samples was found to be having high psychological wellbeing. (42.9\%) of the samples with intermediate psychological wellbeing. About (68.3\%) of the samples found to be having normal self-esteem. (30.2\%) of the samples with low self-esteem and only (1.6\%) participant was having high self-esteem. There is no significant relationship was found between psychological wellbeing and self-esteem. Health professionals, mental health nurses have an important role to acknowledge the burden of the caregivers. They are in a position to render support and refer to get further support through social workers and communityagencies.

\section{Acknowledgement:}

We acknowledge all the subjects who participated in the study willingly.

6. Rosenberg, M. (1965). Society and the adolescent self-image. Princeton, NJ: Princeton University Press.

7. O'Connell KL.J ournal of Child \& Adolescent Psychiatric Nursing .What can we learn? Adult outcomes in children of seriously mentally ill mothers [internet][updated on 2009 Dec 18] [cited on 2013 Feb18]. Available from:http://web.ebscohost.com/ehost/pdfviewer / pdfviewer?sid=d4463437-85af- 4762-b5a0-6edfac2a61a3\%40 sessionmgr $115 \&$ vid $=4 \&$ hid $=113$.

8. Noonan AE, Tennstedt SL. M eaning in caregiving and its contribution to caregiver well-being. Gerontologist. 1997 Dec; 37 (6): 785-94. (52 ref). Available from: http://web.ebscohost.com/ehost/detail?vid $=8 \&$ sid $=75 c 70$ c $8 b-d f 93-4459$. 